\section{Has the panda had its day?}

Mammals comprise a relatively small proportion of the world fauna -4000 or so species compared with an estimated total of between 5 and 10 million (of which 1.5-1.8 million have been described). Yet, over the last decade half of the papers published in Oryx have had mammals as their primary focus; indeed, in this issue all the main articles deal with mammals. This probably reflects the fact that conservation biologists and ecologists devote a proportionally large amount of conservation effort to mammal species: for example, Fauna \& Flora International's $100 \%$ Fund gave support to 584 projects between 1971 and 1996, and half of these were concerned with some aspect of mammal conservation.

Why this bias? As mammals ourselves, it is perhaps not surprising that we find other mammals very interesting and that we want to conserve them. The 250 or so people who packed the Meeting Rooms at the Zoological Society of London on 14-15 November 1997 confirmed that interest. They were there to attend a symposium entitled 'Has the Panda had its Day? Future Priorities for the Conservation of Mammalian Biodiversity', which was organized by Fauna \& Flora International and the Mammal Society. The 20 presentations covered a range of issues, including: new techniques for studying mammals; patterns and processes in mammalian extinctions; the problems and benefits of using mammals as flagship species; which species benefited from the protected areas that were originally designed by game hunters; mammals as indicators of changes in biodiversity; the role of Red Data Books and Action Plans; methods of identifying priority areas; why the conservation focus has been on large rather than small mammals; and priorities for captive breeding. Lu Zhi reported on Chinese research on the panda - among the most potent symbols of conservation - that revealed that the wild population is 'having a good day' in that its reproduction in the wild is adequate and that the population has remained stable for 20 years. However, habitat decline is a huge problem, with logging in panda habitat outside reserves now being the major threat. To tackle this an integrated conservation and development project has been initiated to address the root causes of the logging.

Such approaches are becoming more and more urgently needed. In the opening paper Jeffrey McNeely made a plea for those seeking to conserve mammals to find new ways of doing so. Using the IUCN/SSC Wild Cat Action Plan and Asian Rhino Action Plan as examples, he pointed out that, of the 105 actions recommended for cats, 71 per cent were for research and survey work, and of 57 actions recommended for Asian rhinos, 39 per cent were for intensive protection/antipoaching work. These actions are valid but even if all were achieved with 100 per cent success it would not be enough to stem the tide of extinction. Twenty-four per cent of mammals are in IUCN's three highest categories of threat and the outlook does not seem to be improving.

What is needed is for mammal conservationists to find ways to tackle the underlying causes of proximate threats such as habitat destruction, overexploitation and introduced species. We must be creative and link mammal conservation needs to the global concerns about climate change and desertification. We must get economists on our side to point out the folly of destroying wild habitat by paying agricultural subsidies.

McNeely argued that a biodiversity approach was an effective way to do this because the concept had caught the attention of the world's leaders and decision makers. The Convention on Biological Diversity offers a comprehensive approach for dealing with conservation problems, covering ecological, economic and social aspects. With 170 countries having signed the convention since it came into force in 1993, it offers new opportunities for generating political and public support for mammal conservation. As McNeely concluded, it is up to us to ensure that mammals become an effective part of the new systematic biodiversity approach to conservation.

Jacqui Morris Editor 